Pacific Journal of Mathematic 


\title{
ON NORMALITY AND POINTWISE PARACOMPACTNESS
}

\author{
D. R. Traylor and J. N. Younglove
}

The primary purpose of this paper is to establish some implications between normality and pointwise paracompactness in Moore spaces. In particular, it is proved that if either of two conjectures, raised by $R$. W. Heath and E. E. Grace, is true then each normal Moore space is indeed metrizable.

In [4], Heath and Grace raised questions regarding the substitution of normality for the condition of pointwise paracompactness in several of the theorems proved in that paper. The resulting statements appear below as Conjecture $\mathrm{A}$ and Conjecture $\mathrm{B}$. The purpose of this note is to establish that the truth of either of the conjectures implies that each normal separable Moore space is metrizable. Thus, if either Conjecture A or Conjecture B is proved true then the condition that $2^{\aleph_{0}}<2^{\aleph_{1}}$ would be removed from Jones' result [8, Th. 5] on the metrization of normal separable Moore spaces.

For definitions and results related to the question of metrization of normal Moore spaces, refer to [1], [2], [5], [6], [7], [8], [9], [10], $[11],[13],[14]$.

ConjeCture A. Suppose that $S$ is a connected normal Moore space such that $S$ contains no cut points and it is true that if each of $P$ and $Q$ is a point of $S$ and $R$ is a region containing $P$ then some separable, closed connected subset $N$ of $R$ separates $P$ from $Q$ in $S$. Then $S$ is separable.

ConjeCture B. Suppose that $S$ is a connected, locally connected, normal Moore space containing a separable closed set which separates $S$ and each separable closed set which separates $S$ contains two points which are separated by a separable closed set. Then $S$ is separable.

Theorem 1. If Conjecture $A$ is true then each normal separable Moore space is metrizable.

Proof. Suppose that the theorem is false and that $(S, \Omega)$ is a normal separable nonmetrizable Moore space. There exist 18, Lemma $C]$, in $S$, an uncountable set $M$ with no limit point and a countable dense set $K$ of $S-M$ such that each point of $M$ is a limit point of $K$. The subspace $K+M$, with the relative topology, is normal, separable, nonmetrizable and a Moore space. If $\left(S_{1}, \Omega_{1}\right)$ denotes the subspace $K+M$ of $(S, \Omega)$, denote by $\left(S_{1}, \Omega_{2}\right)$ the space whose topology 
is precisely that of $\left(S_{1}, \Omega_{2}\right)$ of [2, Th. 2]. For purposes of clarity, this definition is included below:

Enumerate $K: A_{1}, A_{2}, A_{3} \cdots$. For each point $x$ of $M$ denote by $\left\{n_{i}(x)\right\}_{i=1}^{\infty}$ an increasing sequence of positive integers such that limit ${ }_{i \rightarrow \infty}$ $A_{n_{i}}(x)=x$, according to the topology $\Omega_{1}$. Now consider the space $\left(S_{1}, \Omega_{2}\right)$, where $\Omega_{2}$ is the topology induced by the following definition of region:

The point set $R$ is a region if and only if either (1) for some point $P$ of $K, R$ is the degenerate set whose only element is $P$, or (2) some point $x$ of $M$ and some positive integer $i, R$ is the set to which $P$ belongs if and only if $P=x$ or $P=A_{n j}(x)$ for some $j$ greater than or equal to $i$.

Using the method employed in [12, Th. 3] (that of inserting copies of open intervals of the real line between "adjacent" points of $K$ which are points of a region containing a point of $M$ ) it is seen that it is possible to embed $\left(S_{1}, \Omega_{2}\right)$ in a space $\left(S_{2}, \Omega_{3}\right)$ which is normal, separable, nonmetrizable, arcwise connected, and locally arcwise connected. Indeed, (using precisely the notation of [2, Th. 2]), if $A_{i}$ is a point of $K$, at most finitely many intervals "connect" $A_{i}$ to points of $K$ having subscripts less than $i$, and at most countably many intervals "connect" $A_{i}$ to points of $K$ having subscripts greater than $i$.

Now, denote by $Z$ a space with discrete topology such that $\overline{\bar{Z}}=\overline{\bar{M}}$ and $Z$ does not intersect $S_{2}$. There is a reversible transformation $T$ which throws $Z$ onto $M$.

Consider the topological product space, $Z \times[0,1)$. It follows that $T$ induces a reversible transformation $T^{1}$ from $Z \times\{0\}$ onto $M$ such that if $m$ is a point of $M$ then there exists a point $z$ of $Z$ such that $T^{1}(z, 0)=m$, where $(z, 0)$ is a point of $z \times[0,1)$. This essentially attaches mutually exclusive segments to the points of $M$.

Denote by $\left(S_{3}, \Omega_{4}\right)$ the space in which "point" means point of $S_{2}$ or point of $z \times[0,1)$ for some $z$ of $Z$ and in which $\Omega_{4}$ is the topology induced by the following definition of region:

The point set $R$ is a region if and only if either.

(i) there is a region $g$ of $\Omega_{3}$ such that $g$ contains no point of $M$ and $g=R$, or

(ii) there is a region $g$ of $\Omega_{3}$ such that $g$ contains a point of $M$, say $m$, and $R$ is the set to which $x$ belongs if and only if $x$ is a point of $g$ or, for some positive integer $n$ and some point $z$ of $A$ such that $T^{1}(z, 0)=m, x$ is a point of $z \times[0,1 / n)$, or

(iii) there are a point $z$ of $Z$ and a positive integer $n$ such that $R$ is a subsegment of $z \times(0,1)$ of length less than $1 / n$.

It follows that $\left(S_{3}, \Omega_{4}\right)$ is a normal, nonmetrizable, arcwise con- 
nected Moore space which contains uncountably many mutually exclusive domains.

Now denote by $\left(S_{4}, \Omega_{5}\right)$ the space which is the topological product space resulting from $\left(S_{3}, \Omega_{4}\right)$ being crossed with $(0,1)$. It follows from Dowker's result [3, Th. 2] that each normal Moore space is countably paracompact. Dowker also proved [3, Th. 4] that if $X$ is countably paracompact and normal then the topological prodoct $X \times I$ of $X$ with the closed line interval $I=[0,1]$ is normal. Since the product of a normal Moore space with the interval $[0,1]$ is again a normal Moore space and each such space is completely normal [8, Th. 6], it is evident that $\left(S_{4}, \Omega_{5}\right)$ is normal. Indeed, $\left(S_{4}, \Omega_{5}\right)$ is an arcwise connected, locally arcwise connected Moore space which contains no cut points and is such that if each of $x$ and $y$ is a point of $S_{4}$ and $R$ is an open set containing $x$ then there is a closed, connected, separable subset $N$ of $R$ such that $N$ separates $x$ from $y$ in $S$. However, $\left(S_{4}, \Omega_{5}\right)$ is definitely not separable since its construction insists upon the existence of uncountably many mutually exclusive domains.

THeorem 2. If Conjecture $B$ is true then each normal separable Moore space is metrizable.

Proof. The example constructed in the proof of Theorem 1 would deny Conjecture $B$.

\section{BiBLIOGRAPHY}

1. R. H. Bing, Metrization of topological spaces, Canad. J. Math. 3 (1951), 175-186.

2. C. H. Dowker, On countably paracompact spaces, Canad. J. Math. 3 (1951), 219-224.

3. B. Fitzpatrick and D. R. Traylor, Two theorems on metrizability of Moore spaces, Pacific J. Math. 19 (1966), 259-264.

4. E. E. Grace and R. W. Heath, Separability and metrizability in pointwise paracompact Moore spaces, Duke Math. J. 31 (1964), 603-610.

5 . R. W. Heath, A non-pointwise paracompact Moore space with a point-countable base (to appear).

6. - Screenability, pointwise paracompactness and metrization of Moore spaces, Canad. J. Math. 16 (1964), 763-770.

7. - Separability and $\boldsymbol{\aleph}_{1}$-compactness, Coll. Math. 12 (1964), 11-14.

8. F. B. Jones, Concerning normal and completely normal spaces, Bull. Amer. Math. Soc. 43 (1937), 671-67\%.

9. M. Katetov, On real valued functions in topological spaces, Fund. Math. 38 (1951), $85-91$.

10. R. L. Moore, Foundations of Point Set Theory, Amer. Math. Soc. Coll. Publ. 13, Revised Edition, Providence, 1962.

11. Hing Tong, Some characterizations of normal and perfectly normal spaces, Duke Math. J. 19 (1952), 289-292.

12. D. R. Traylor, Normal, separable Moore spaces and normal Moore spaces, Duke Math. J. 30 (1963), 485-493.

13. - Metrizability in normal Moore spaces, Pacific J. Math. 19 (1966), 175-181. 
14. J. N. Younglove, Concerning metric subspaces of non-metric spaces, Fund. Math. 48 (1959), 15-25.

Received April 14, 1967. The first author was supported partially by NASA Grant NGR 44-005-010 and the second author was supported partially by NASA Grant 44-005-037.

UNIVERSITY OF HOUSTON

Houston, TEXAS 


\section{PACIFIC JOURNAL OF MATHEMATICS}

\section{EDITORS}

H. ROYDEN

Stanford University

Stanford, California

\section{J. P. Jans}

University of Washington

Seattle, Washington 98105

\section{J. DUGUNDJI}

Department of Mathematics University of Southern California Los Angeles, California 90007

\section{RICHARD ARENS}

University of California

Los Angeles, California 90024

\section{ASSOCIATE EDITORS}

E. F. BECKENBACH

B. H. NEUManN

F. WOLF

K. YosIDA

\section{SUPPORTING INSTITUTIONS}

UNIVERSITY OF BRITISH COLUMBIA CALIFORNIA INSTITUTE OF TECHNOLOGY UNIVERSITY OF CALIFORNIA MONTANA STATE UNIVERSITY UNIVERSITY OF NEVADA NEW MEXICO STATE UNIVERSITY OREGON STATE UNIVERSITY UNIVERSITY OF OREGON OSAKA UNIVERSITY UNIVERSITY OF SOUTHERN CALIFORNIA
STANFORD UNIVERSITY

UNIVERSITY OF TOKYO UNIVERSITY OF UTAH WASHINGTON STATE UNIVERSITY UNIVERSITY OF WASHINGTON AMERICAN MATHEMATICAL SOCIETY CHEVRON RESEARCH CORPORATION TRW SYSTEMS NAVAL WEAPONS CENTER 


\section{Pacific Journal of Mathematics}

\section{Vol. 25, No. $1 \quad$ September, 1968}

Glen Eugene Bredon, Cosheaves and homology................... 1

Robin Ward Chaney, A chain rule for the transformation of integrals in

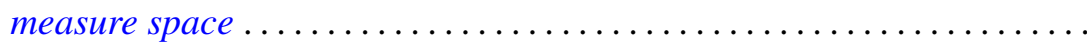

Colin W. Clark, On relatively bounded perturbations of ordinary differential operators................................... 59

John Edwin Diem, A radical for lattice-ordered rings.............. 71

Zeev Ditzian, On a class of convolution transforms ................ 83

Dennis Garoutte and Paul Adrian Nickel, A note on extremal properties characterizing weakly $\lambda$-valent principal functions............. 109

Shwu-Yeng Tzeng Lin, Fixed point properties and inverse limit spaces . . . 117

John S. Lowndes, Some dual series equations involving Laguerre polynomials ................................. 123

Kirti K. Oberai, Sum and product of commuting spectral operators ....... 129

J. N. Pandey and Armen H. Zemanian, Complex inversion for the generalized convolution transformation..................... 147

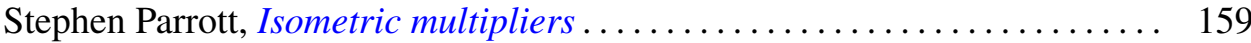

Manoranjan Prasad, Note on an extreme form .................. 167

Maciej Skwarczyński, A representation of a bounded function as infinite product in a domain with Bergman-Shilov boundary surface ......... 177

John C. Taylor, The Šilov boundary for a lattice-ordered semigroup ...... 185 Donald Reginald Traylor and James Newton Younglove, On normality and pointwise paracompactness ............................. 193

L. Tzafriri, Quasi-similarity for spectral operators on Banach spaces ... 